\title{
Assessing How Exercise is Medicine - On Campus (EIM-OC) Movement is Operationalized at Campuses
}

\author{
Bryson Long \& Young Sub Kwon
}

Human Performance Lab

Humboldt State University, California, USA

\begin{abstract}
Researchers reported that about $40 \%$ to $50 \%$ of college students are physically inactive (Keating et al., 2005), and physical inactivity among college students has been a prevalent issue. Exercise Is Medicine On Campus (EIM-OC) has been developed to combat this growing trend. Implementation of this program may be vital to its success in improving physical activity levels. However, there has been very little research into assessing how EIM-OC operates on various university campuses throughout the world. Therefore Wilson et al., (2018) developed a survey to evaluate EIM-OC implementation and outcomes at various institutions.
\end{abstract}

Keywords: physical inactivity, college students, Exercise is Medicine (EIM)

Article History

Received 23 September 2020

Accepted 20 October 2020

Published 31 January 2021

Available online 19 February 2021

https://doi.org/10.47544/johsk.2021.2.1.18

Corresponding Author
Young Sub Kwon
young.kwon@humboldt.edu
Department of Kinesiology and Recreation Administration
College of Professional Studies
Humboldt State University, California, USA

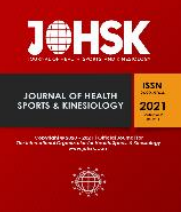

\section{Methods}

159 representatives were sent a cross-sectional mixed-method survey online that collected data from universities currently participating in EIM-OC. The data collected was based on one or more characteristics of their EIM-OC programs. These characteristics include the size of the university, background information on their EIM-OC programs (Date they began EIM-OC, program home, program focus, if they had an EIM-OC ambassador, and selection of student leaders and level of student involvement) and current challenges that programs face.

\section{Results}

41 responses were used with student wellness making up the majority of programs ( $n=61.98 \%$ ) followed by faculty/staff wellness ( $n=22.43 \%$ ) with community wellness rounding it out ( $n=15.59 \%)$. Students' involvement played a critical role in many program's successes. Student roles varied from promotion, leadership/organization/planning, education, program implementation, and data collection (Table 1).

\section{Journal of Health, Sports, \& Kinesiology | ISSN 2692-9864 | www.johsk.com}


Table 1. Number of Students Roles in Exercise Is Medicine On Campus (EIM-OC).

\begin{tabular}{cc} 
Student Involvement & Number of Roles \\
Program Promotion & 20 \\
Student Leadership/Organization/Planning & 18 \\
Student Education & 16 \\
Program Implementation & 14 \\
Data Collection & 10 \\
\hline
\end{tabular}

Note: Taken from Table 2 from Wilson et al. (2018).

\section{Discussion}

Student involvement is the key to the success of EIM-OC programs on university campuses; therefore, most of the universities had a majority of their effort focused on student wellness. Having well-defined roles for students to participate in led to the majority of successes in many programs across multiple campuses. However, it was noted that many programs could not meet the demand for improving student's physical activity level due to several shortcomings among the programs and the sheer number of students involved.

\section{Critique}

Assessing this survey journal article, we found that most campuses' EIM-OC programs did only awareness programs but did not practice exercise as medicine. The Humboldt State University EIM-OC team decided to do things differently compared to other universities, so we have provided an awareness program as well as the 12-week Daily $5 \mathrm{~km}$ program for students, faculty, and staff during the academic year. The Daily $5 \mathrm{KM}$ is a simple and free program that gets students and faculty out of the classroom and school staff out of the office for 25 to 30 minutes every day to run or jog, at their own pace, with their classmates and peers making them fitter and healthier. Some of the health benefits The Daily $5 \mathrm{KM}$ program provides student and faculty is increased cardiovascular health, stamina, energy levels. It will also help in maintaining a healthy weight level and is also great stress and anxiety reducer. Therefore, we recommended the Daily $5 \mathrm{KM}$ should be used in current and future programs as one of the EIM-OC movement practices.

\section{References}

Wilson, O. W., Bhuiyan, N., Papalia, Z., \& Bopp, M. (2018). The implementation and outcomes of Exercise Is Medicine on Campus. Translational Journal of the ACSM, 3(20), 158-168. doi:10.1249/tjx.0000000000000071

Calestine, J., Bopp, M., Bopp, C. M., \& Papalia, Z. (2017). College student work habits are related to physical activity and fitness. International Journal of Exercise Science, 10(7), 1009-1017.

Keating, X. D., Guan, J., Piñero, J. C., \& Bridges, D. M. (2005). A Meta-Analysis of College Students' Physical Activity Behaviors. Journal of American College Health, 54(2), 116-126. doi:10.3200/jach.54.2.1 16-126 